Pesq. Vet. Bras. 29(3):263-265, março 2009

\title{
Surto de tétano em búfalos (Buballus bubalis) no Estado do Pará
}

\author{
José Diomedes Barbosa ${ }^{2}$, Marcos D. Duarte ${ }^{2}$, Carlos Magno C. Oliveira², \\ José Alcides S. Silveira ${ }^{2}$, Tatiane T. Albernaz ${ }^{2}$ e Valíria D. Cerqueira ${ }^{2}$
}

\begin{abstract}
Barbosa J.D., Dutra. M.D. Oliveira C.M.C., Silveira J.A.S., Albernaz. T.T. \& Cerqueira V.D. 2009. [Outbreak of tetanus in bufalloes (Buballus bubalis) in Pará, Brazil.] Surto de tétano em búfalos (Buballus bubalis) no Estado do Pará. Pesquisa Veterinária Brasileira 29(3):263-266. Central de Diagnóstico Veterinário, Universidade Federal do Pará, Rua Maximino Porpino da Silva 1000, Pirapora, Castanhal, PA 68743080, Brazil. E-mail: diomedes@ufpa.br

An outbreak of tetanus in Murrah buffaloes in Belém, state of Pará, Brazil, is described. The outbreak was observed in a flock of 250 buffaloes, 80 of which were vaccinated intramuscularly in the croup against rabies. Four buffaloes fell ill 15 to 19 days after vaccination, one died after a clinical course of 2 days, one was submitted to euthanasia in extremis on the $7^{\text {th }}$ day after the onset of symptoms, and two others recovered within 2 weeks after treatment with penicillin for 4 days and anti-tetanic serum. The first symptoms observed were prolapse of the third eyelid, especially when the animal was stimulated, followed by a rigid walk, as difficulty in inflexing the members and lateral recumbence with the members extended, besides very open eyelids, sialorrhea, hyperexcitability, erect ears and slight lockjaw, and food accumulation in the oral cavity. At post-mortem examination was found a focus of yellowish pus in the croup muscles, where the vaccine had been applied. At histopathology no significant alterations in internal organs were observed. Based on the clinical picture, the epidemic data and absence of histological lesions, the diagnosis of tetanus was established. The infection was considered to be due to the use of dirty needles used during vaccination.
\end{abstract}

INDEX TERMS: Buffaloes, tetanus, Pará.

RESUMO.- Descreve-se um surto de tétano em búfalos da raça Murrah em uma propriedade situada no município de São Caetano de Odivelas, localizado na região metropolitana de Belém, estado do Pará. Do rebanho de 250 bubalinos, 80 animais foram vacinados contra raiva por via intramuscular na região da garupa. Em um período de 15 a 19 dias após a vacinação quatro animais adoeceram, um morreu com dois dias de evolução, um foi eutanasiado in extremis no sétimo dia após o início dos sinais clínicos e os demais se recuperaram após tratamento. Nos bubalinos, o primeiro sinal clínico observado foi o prolapso da terceira pálpebra, em especial quando o animal era estimulado, seguido por andar rígido, manifestado por dificuldade de

\footnotetext{
${ }^{1}$ Recebido em 5 de novembro de 2008.

Aceito para publicação em 28 de novembro de 2008.

2 Central de Diagnóstico Veterinário (CEDIVET), Universidade Federal do Pará, Rua Maximino Porpino da Silva 1000, Pirapora, Castanhal, PA 68743-080, Brazil. *Autor para correspondência: diomedes@ufpa.br
}

flexão dos membros e permanência em decúbito lateral com os membros estendidos, pálpebras muito abertas, sialorréia, hiperexcitabilidade, orelhas eretas, leve trismo e acúmulo de alimento na cavidade oral. À necropsia foi evidenciada uma área de coloração amarelada com presença de exsudação purulenta na musculatura da região da garupa, local de aplicação da vacina. Ao exame histopatológico não foram evidenciadas alterações significativas. Em dois animais foi realizado tratamento com penicilina por via intramuscular e soro antitetânico por via intramuscular e sub-aracnóide; após duas semanas esses animais se recuperaram. Diante do quadro clínico, dos dados epidemiológicos e da ausência de lesões histológicas foi feito o diagnóstico de tétano. Concluiu-se que o tétano é uma doença a ser considerada na bubalinocultura no Brasil. A infecção, provavelmente ocorreu durante o procedimento de vacinação, através injeções intramusculares utilizando aguIhas contaminadas.

TERMOS DE INDEXAÇÃO: Búfalos, tétano, Pará. 


\section{INTRODUÇÃO}

O tétano é uma doença infecciosa não contagiosa, altamente fatal, causada por toxinas produzidas por Clostridium tetani, uma bactéria anaeróbia Gram-positiva, formadora de esporos, encontrada no solo, no trato digestivo e nas fezes dos animais (Radostits et al. 2002, Stöber 2005). Na maioria dos casos o local da infecção é uma ferida perfurante profunda, onde os esporos permanecem latentes e produzem doença somente quando as condições tissulares favorecem a sua proliferação (Radostits et al. 2002). Mas surtos de tétano já foram observados em bovinos alimentados com palha, provavelmente causando lesões no trato digestivo, possibilitando a penetração da bactéria (Preece \& Bostelmann 1996, Whitehead \& Ellicott 1996). Na maioria das espécies susceptíveis a doença desenvolve-se entre uma e três semanas após a infecção (Radostits et al. 2002; Smith 2006). Os sinais clínicos são semelhantes nas várias espécies. Inicialmente ocorre aumento da rigidez muscular, acompanhada por tremores, trismo e prolapso da terceira pálpebra; adicionalmente são observados expressão alerta com posicionamento ereto das orelhas, retração das pálpebras, dilatação das narinas, timpanismo leve e hiperestesia. (Whitehead \& Ellicott 1996, Radostits et al. 2002). Exceto pela ferida onde ocorreu anaerobiose, não existem lesões macroscópicas ou microscópicas observáveis no tétano (McGavin \& Zachary 2007). No Brasil, a ocorrência desta enfermidade em geral é esporádica, mas surtos têm ocorrido em bovinos após a aplicação de produtos manuseados em currais, pelo uso de equipamentos não higienizados ou através da contaminação da pele por poeira ou lama durante práticas de vacinação e vermifugação (Dutra et al. 2001). Não foram encontrados dados na literatura sobre a ocorrência de tétano em bubalinos no Brasil. Dessa forma, o presente trabalho tem por objetivo descrever surto de tétano ocorrido em bubalinos no Brasil.

\section{MATERIAL E MÉTODOS}

Os dados epidemiológicos e clínico-patológicos da enfermidade foram obtidos em visita a uma propriedade situada no município de São Caetano de Odivelas, localizado na região metropolitana de Belém, estado do Pará. Foi realizado o exame clínico dos animais doentes, com exceção do primeiro animal que já havia morrido. Um dos animais foi eutanasiado segundo as normas descritas pelo COBEA (1979) e necropsiado. Fragmentos de órgãos diversos coletados para exame histopatológico foram fixados em formalina a $10 \%$, processados pelos métodos rotineiros, incluídos em parafina, cortados na espessura de $5 \mu$ e corados pela hematoxilina-eosina (HE).

\section{RESULTADOS}

O surto de tétano foi observado em um rebanho de 250 bubalinos de todas as categorias, da raça Murrah, no mês de março de 2007, dos quais 80 animais foram vacinados contra raiva por via intramuscular na região da garupa, usando pistola com agulhas de metal de calibre 40x16. Segundo o tratador, os animais apresentavam grande quantidade de lama na superfície do corpo, que às vezes precisava ser retirada para a introdução da agulha no local da vacinação. Em um período de 15-19 dias após a vacinação quatro animais adoeceram; o Bubalino 1 morreu após dois dias de evolução, o Bubalino 2 foi eutanasiado in extremis no sétimo dia após o início dos sinais clínicos e os Bubalinos 3 e 4 se recuperaram após tratamento. Dados como idade, sexo, início dos sinais clínicos após a vacinação, evolução e desfecho do quadro clínico constam no Quadro 1. Os sinais clínicos observados foram inicialmente prolapso da terceira pálpebra (Fig.1), principalmente quando o animal era estimulado, seguido por andar rígido, manifestado por dificuldade de flexão dos membros durante a locomoção, permanência em decúbito lateral com os membros estendidos (Fig.3), pálpebras muito abertas, salivação (Fig.2), hiperexcitabilidade, orelhas eretas, leve trismo e acúmulo de alimento na cavidade oral. À necropsia foi evidenciada uma área de coloração amarelada com presença de exsudação purulenta na musculatura da região da garu-

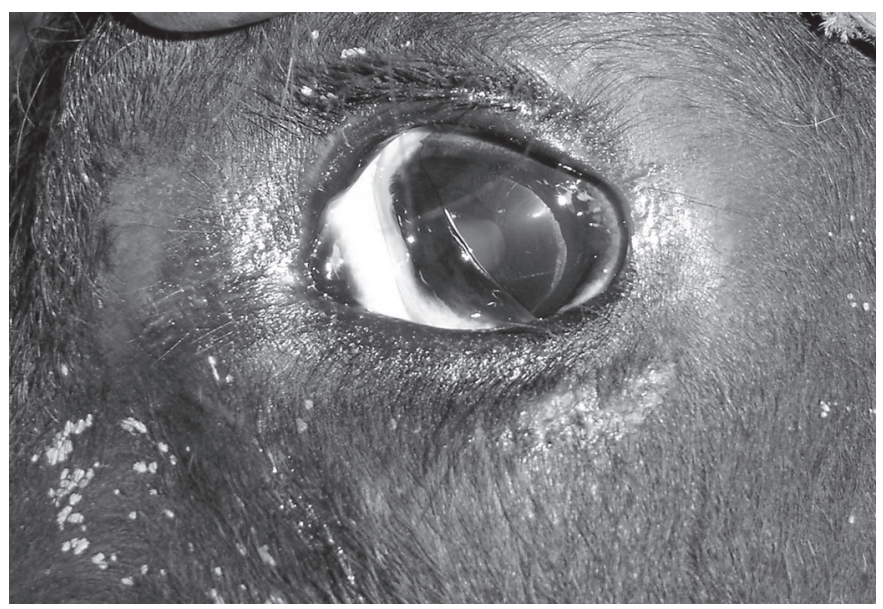

Fig.1. Animal apresentando prolapso da terceira pálpebra.

Quadro 1. Dados epidemiológicos, tratamento, evolução e desfecho, dos animais acometidos por tétano, no Estado do Pará

\begin{tabular}{|c|c|c|c|c|c|c|c|}
\hline Animal & Sexo & Idade & $\begin{array}{l}\text { Início dos sinais } \\
\text { clínicos após a } \\
\text { vacinação }\end{array}$ & $\begin{array}{l}\text { Tratamento } \\
\text { com soro } \\
\text { antitetânico }\end{array}$ & $\begin{array}{c}\text { Tratamento com } \\
\text { Penicilina }^{\mathrm{a}} \\
\text { Ul/kg/dia }\end{array}$ & Evolução & Desfecho \\
\hline Bubalino 1 & Fêmea & 12 meses & 15 dias & - & & 2 dias & Morreu \\
\hline Bubalino 2 & Fêmea & 5 anos & 17 dias & - & & 7 dias & Eutanasiado \\
\hline Bubalino 3 & Fêmea & 10 anos & 19 dias & $\begin{array}{c}10.000 \text { UI, } \\
\text { IM }\end{array}$ & $\begin{array}{c}20.000 \text { por } 4 \text { dias, } \\
\text { IM }\end{array}$ & 16 dias & Recuperou-se \\
\hline Bubalino 4 & Macho & 12 meses & 19 dias & $\begin{array}{l}25.000 \mathrm{UI}, \\
\text { SA }\end{array}$ & $\begin{array}{c}10.000 \text { por } 4 \text { dias, } \\
\text { DO }\end{array}$ & 16 dias & Recuperou-se \\
\hline
\end{tabular}

a Benzilpenicilina procaína, $\mathrm{UI}=$ unidades internacionais, $\mathrm{IM}=$ intramuscular, $\mathrm{SA}=$ sub-aracnóide, $\mathrm{DO}=$ dose única. 
pa, local de aplicação da vacina (Fig.4). Ao exame histopatológico não foram observadas alterações significativas. Em dois animais (Bubalinos 3 e 4) foi realizado o tratamento com penicilina nas doses de 20.000 e $1000 \mathrm{UI}$ por kg/dia, respectivamente, por via intramuscular, durante 4 dias. Desses dois animais, um recebeu soro antitetânico, administra-

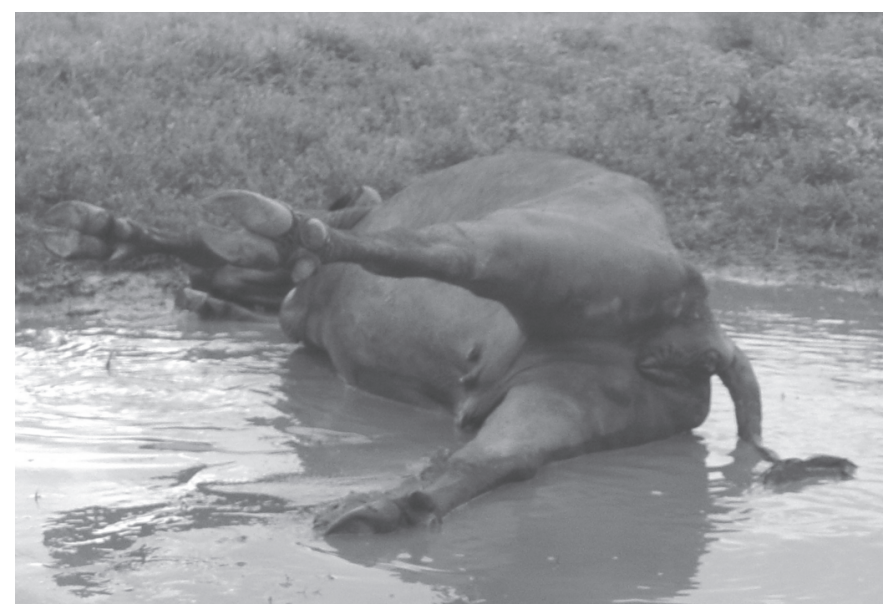

Fig.2. Búfala em decúbito lateral com os membros espáticos.

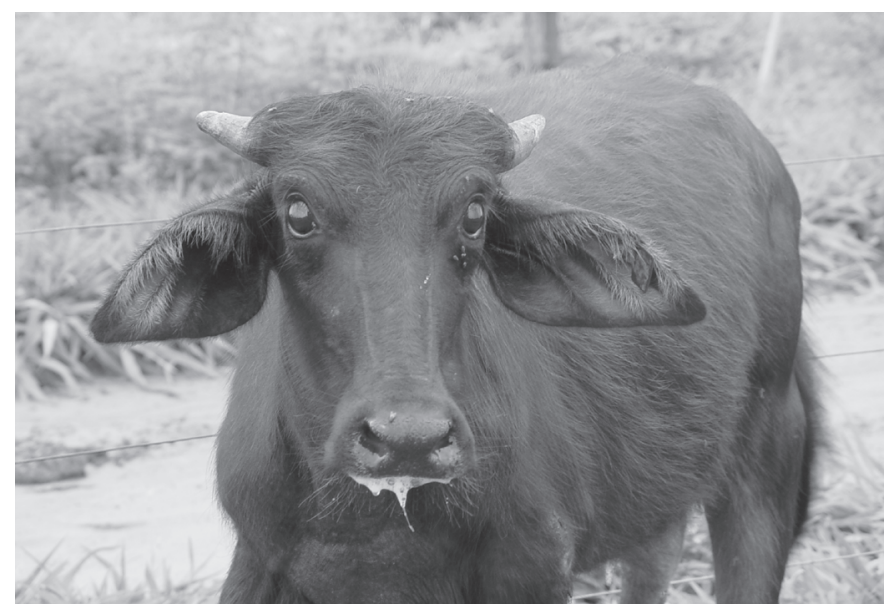

Fig.3. Animal com pálpebras muito abertas e salivação.

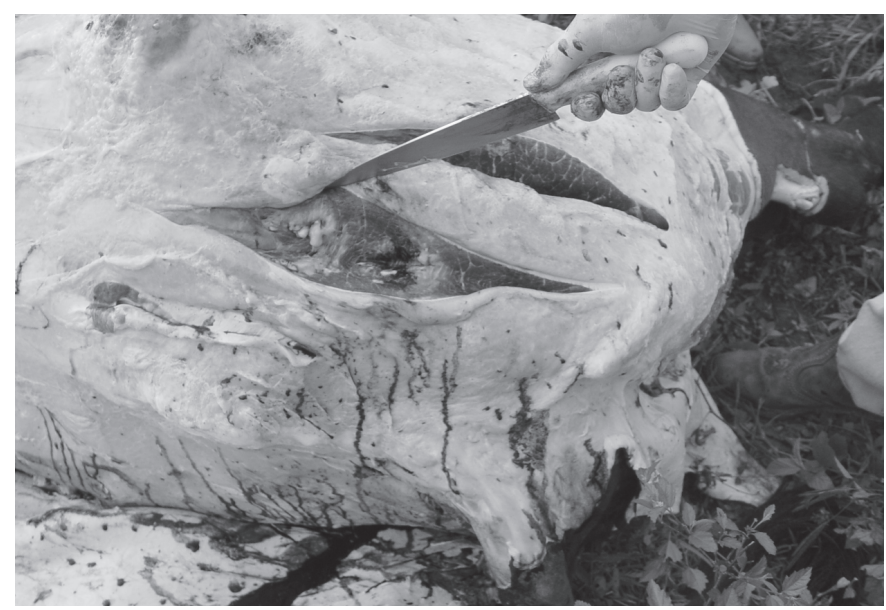

Fig.4. Local da aplicação da vacina, com presença de exudato purulento.. do por via intramuscular na dose de $10.000 \mathrm{UI}$ em dose única (Bubalino 3) e o outro (Bubalino 4) recebeu, também em dose única, $25.000 \mathrm{UI}$, administradas no espaço subaracnóide ao nível da articulação atlanto-occipital. Após duas semanas os animais se recuperaram. Dos 76 animais submetidos à vacinação contra raiva e que não haviam adoecido, 50 receberam 5000 UI de soro antitetânico, por via intramuscular e não adoeceram posteriormente.

\section{DISCUSSÃO E CONCLUSÕES}

Diante do quadro clínico, dos dados epidemiológicos e da ausência de lesões histológicas foi feito o diagnóstico de tétano. O período de incubação de 15-19 dias, observado neste surto, coincide com o de 7-21 dias descrito para a maioria das espécies susceptíveis (Radostits et al. 2002, Smith 2006). Nos bubalinos, o primeiro sinal clínico observado foi o prolapso da terceira pálpebra o que está de acordo com os relatos de Radostits (2002) para a espécie bovina e de Driemeier et al. (2007) para as espécies bovina e ovina, seguido por andar rígido. Por outro lado, Stöber (2005) estabelece que o prolapso da terceira pálpebra é um sinal clínico observado no estado avançado da enfermidade na espécie bovina. A recuperação dos dois animais tratados não é suficiente para afirmar que o búfalo tem uma melhor capacidade de resposta ao tratamento quando comparado a outras espécies, sendo necessários estudos complementares. Concluiu-se que o tétano é uma doença a ser considerada na bubalinocultura no Brasil; apesar de ser considerada uma espécie rústica, medidas de higiene devem ser adotadas durante a administração de medicamentos a bubalinos. A infecção, provavelmente ocorreu durante 0 procedimento de vacinação, através injeções intramusculares utilizando agulhas contaminadas, o que já havia sido relatado por Dutra et al. (2001), na espécie bovina.

\section{REFERÊNCIAS}

COBEA 1979. Lei no 6.638 , de maio de 1979. Colégio Brasileiro de Experimentação Animal, Rio de Janeiro.

Driemeier D., Schild A.L., Fernandes J.C., Colodel E.M., DCorrea A.M., Cruz C.E. \& Barros C.S. 2007. Outbreaks of tetanus in beef cattle and sheep in Brazil associated with disophenol injection. J. Vet. Med. A, Physiol. Pathol. Clin. Med. 54(6):333-353.

Dutra I.S., Ferreira R.M.M., Mingoti G.Z. \& Döbereiner J. 2001. Surto de tétano em bovinos de corte após aplicação de vacina e vermífugos.

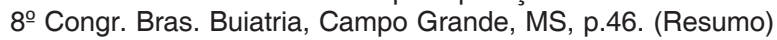

McGavin M.D., Zachary J.F. 2007. Pathologic Basis of Veterinary Disease. 4th ed. Mosby Elsevier, St Louis.

Preece D.L. \& Bostelmann R.W. 1996. Idiopathic tetanus. Vet. Rec. 139:48.

Radostits O.M., Gay C.C., Blood D.C. \& Hinchcliff K.W. 2002. Clínica Veterinária: um tratado de doenças dos bovinos, ovinos, suínos, caprinos e eqüinos, p.677-680. 9 ${ }^{\mathrm{a}}$ ed. Guanabara Koogan, Rio de Janeiro, $1737 p$.

Smith M.O. 2006. Moléstias do Sistema Nervoso: tétano, p.995-998. In: Smith B.P. (Ed.), Tratado de Medicina Interna de Grandes Animais. Manole, São Paulo.

Stöber M. 2005. Tétano, p.968-970. In: Dirksen G., Gründer H. \& Stöber M. (Ed.), Medicina Interna y Cirurgía del Bovino. 4ª ed. Inter-Médica, Buenos Aires.

Whitehead J.G.M. \& Ellicott D.H. 1996. Idiopathic tetanus. Vet. Rec. 138:651. 